\title{
Advance Quantity Meal Preparation Pilot Program Improves Home-Cooked Meal Consumption, Cooking Attitudes, and Self-Efficacy
}

\author{
Shannon Mendez, MS, RD; Jamie Kubota, MS, RD; Adrianne M. Widaman, PhD, RD; \\ John Gieng, PhD
}

\begin{abstract}
Objective: To evaluate the effects of a group-based Advance Quantity Meal Preparation (AQMP) program on the consumption of home-cooked meals, cooking attitudes, and self-efficacy in healthy adults.

Methods: Participants $(n=10)$ in a group setting prepared healthy meals weekly consisting of 10 entrees and 5 snacks for 6 weeks. A survey assessing cooking attitudes, cooking self-efficacy, and cooking behavior and consumption at 3 time points: preprogram, postprogram (T2), and 3 months postprogram (T3).

Results: The AQMP program increased the proportion of overall home-cooked meal consumption (T2, $P=0.03)$, home-cooked dinner consumption (T2, $P=0.04)$, cooking attitudes $(\mathrm{T} 3, P=0.01)$, and cooking self-efficacy (T2, $P=0.002)$.

Conclusions and Implications: This pilot study indicates that AQMP may increase home-cooked meal consumption, cooking attitudes, and cooking self-efficacy.

Key Words: meal, cooking, attitudes, group-based cooking program (J Nutr Educ Behav. 2021;53:608 -613.)
\end{abstract}

Accepted December 29, 2020. Published online February 2, 2021.

\section{INTRODUCTION}

Obesity is an epidemic linked with several noncommunicable diseases such as type 2 diabetes mellitus and heart disease. ${ }^{1}$ In the US, the prevalence of overweight and obesity has steadily risen in recent decades. ${ }^{2}$ Factors including the overabundance and availability of convenience foods, an increase in consumption of energydense foods from sources outside the home, and the decline in cooking skills and nutrition knowledge have contributed to this increase. , $^{1,3}$ Observational studies suggest that eating home-cooked meals more frequently was associated with lower body mass index (BMI) and body fat percentage and an overall healthier diet. $^{5-7}$ However, lack of time, nutrition knowledge, and cooking skills were barriers to cooking at home. ${ }^{6}$ Interventions that included hands-on cooking classes, nutrition education programs, or group classes focused on menu plans and portion control were reported to increase cooking skills, increase confidence with meal preparation, and reduce financial expenditure on takeaways or fast foods. ${ }^{8-11}$ Although these interventions evaluated cooking skills, cooking attitudes and behaviors, and cooking self-efficacy, there are limited data on programs or interventions that overcome the barrier of time constraint while promoting home-cooked meal preparation and consumption. Evidence suggests that commercially prepared

Department of Nutrition, Food Science, and Packaging, San José State University, San José, CA

Conflict of Interest Disclosure: The authors have not stated any conflicts of interest.

Address for correspondence: John Gieng, PhD, Department of Nutrition, Food Science, and Packaging, San José State University, One Washington Square, San José, CA 95192-0058; Email: john.gieng@sjsu.edu

(C) 2021 The Authors. Published by Elsevier Inc. on behalf of Society for Nutrition Education and Behavior. This is an open access article under the CC BY license (http:// creativecommons.org/licenses/by/4.0/)

and preportioned meals in conjunction with counseling promoted sustained and significant weight loss. ${ }^{12}$ Combining hands-on cooking with a pre-prepared meal intervention may have a positive effect on both cooking behaviors and health-related measures.

Advance quantity meal preparation (AQMP) is the process of planning and preparing meals in bulk, ahead of time, to eat later. The AQMP program was a 6-week group-based intervention designed to increase consumption of home-cooked meals by overcoming barriers, including lack of time. This program was also designed to increase cooking self-efficacy and promote positive and healthy cooking attitudes and behaviors. ${ }^{8,10,11,13}$ The goal of this program was to promote the long-term adoption of behaviors related to pre-preparing portioned meals to increase home-cooked meal consumption, which in turn may positively affect health outcomes. In the present pilot study, the primary aim was to determine whether this 6-week group-based AQMP program affected the consumption of home-cooked meals in healthy adults; the secondary aim was to determine whether the 
program affected cooking attitudes and cooking self-efficacy. It was hypothesized that this program would reduce barriers to consuming homecooked meals and increase consumption of home-cooked meals.

\section{METHODS}

\section{Study Design}

The AQMP program was evaluated in a pre-experimental pilot study on healthy adult members of a fitness center in Santa Clara, CA, in early 2019. Program development focused on perceived barriers of home-cooking and self-efficacy related to cooking skills. ${ }^{8,10,11,13}$ The AQMP program addressed the barrier of perceived time constraints, which is one of the most widely reported barriers to homecooked meal consumption. ${ }^{14,15}$ It did this by demonstrating that a large portion of weekly meal preparation can be consolidated into a concerted effort, using less overall time. Self-efficacy was also fostered by allowing the participants to practice new cooking skills each week in a socially supportive, group-based environment.

Participants met for 6 consecutive Sundays from $8 \mathrm{AM}$ to $12 \mathrm{PM}$ at a commercial kitchen, where the facilitator assigned various tasks (eg, chopping and trimming vegetables, preparing and cooking protein such as ground turkey, and baking) as needed for group-based AQMP. Collectively, the participants prepared, portioned, and packaged meals and snacks in bulk to be consumed during the following week. Each participant received 10 individually packed and portioned meals and 5 individual snacks per week. The facilitator suggested 1 portioned meal be consumed for each lunch and dinner during the 5-day work week. Participants were free to supplement with food and beverage ad libitum throughout the week and weekend. A program fee per week of $\$ 100$ covered food (\$46.89/person/ wk), reusable food packaging containers $(\$ 13.07 /$ person), supplies ( $\$ 5.52 /$ person/wk), and the kitchen rental/ miscellaneous (\$45.41/person/wk). Each meal (mean $\pm \mathrm{SD}$ ) contained an estimated $664 \pm 143 \mathrm{kcal}, 59 \pm 16 \mathrm{~g}$ of carbohydrates, $43 \pm 14 \mathrm{~g}$ of protein, $29 \pm 10 \mathrm{~g}$ of fat, and $8 \pm 3 \mathrm{~g}$ of fiber, and each snack contained $389 \pm 11$ kcal, $33 \pm 3 \mathrm{~g}$ of carbohydrates, $15 \pm$ $0.2 \mathrm{~g}$ of protein, $24 \pm 0.05 \mathrm{~g}$ of fat, and $6 \pm 0.4 \mathrm{~g}$ of fiber. Before each meeting, the menus, recipes, and ingredients were designed and acquired by the program facilitator (S.M.), who holds a master's degree in nutritional science, has experience leading group classes, and has led AQMP programs in the past. Appropriateness for bulk preparation, available equipment, and likelihood for participant acceptance informed standardized recipes. In accordance with the Dietary Guidelines for Americans, 2015-2020, ${ }^{16}$ recipes emphasized lean meats, whole grains, and fruits and vegetables, in addition to low added sugar, sodium, and saturated fat. Cooking education included verbal instructions, demonstrations, and time-saving techniques. The program facilitator provided oneon-one skill demonstration, as needed. After the completion of the 6-week program, participants received copies of the recipes used and reusable food containers to help support AQMP behaviors and practices at home.

To determine if the AQMP program increased home-cooked meal consumption, participants were assessed preprogram (T1), postprogram (T2), and 3 months postprogram (T3).

\section{Participants}

Subjects were recruited using a convenience sampling strategy via email and social media posts from a fitness center in Santa Clara, CA. Participants were included if they were aged at least 18 years and could stand and work in a kitchen for 4 hours continuously without assistance. A maximum of 10 participants were included in the cohort because of kitchen space limitations. The San José State University Institutional Review Board approved the study protocol, and researchers obtained written consent from each participant before the commencement of the study.

\section{Frequency of Home-Cooked Meal Consumption and Cooking Behaviors}

A web-based survey (Qualtrics, Provo, UT) was administered at T1, T2, and T3 to collect self-reported home- cooked meal consumption, cooking attitudes, cooking self-efficacy, and AQMP acceptance. Six home-cooking consumption questions were created de novo for this study and asked participants to report "in the past 30 days, how many times per week on average did you consume breakfast, lunch, and/or dinner" and "in the past 30 days, how many times per week on average did you consume a home-made breakfast, lunch and/or dinner."

To measure cooking attitudes and self-efficacy, the survey asked 25 Likert scale questions from the validated Cooking With a Chef tool (unpublished data, Michaud P, "Development and Evaluation of Instruments to Measure the Effectiveness of a Culinary and Nutrition Education Program [master's thesis]" Clemson University, 2007). ${ }^{13,17}$ In addition, the survey assessed the frequency of AQMP by defining AQMP and asking, "in the past 30 days, how many times have you batch meal prepped?" Finally, to assess attitudes related to AQMP, 2 Likert scale questions were created de novo: "I am familiar with advance quantity meal prep techniques" and "I am confident utilizing advance quantity meal prep techniques." The research team and 1 outside volunteer independently evaluated these questions for face validity.

\section{Anthropometrics and Dietary Intake}

To monitor a subset of health-related measures of the participants, researchers collected anthropometric and dietary composition data. At T1, T2, and T3 height were measured to the closest $0.1 \mathrm{~cm}$ using a stadiometer (model 213, Seca, Hamburg, Germany, 2014), weight to the closest $0.1 \mathrm{~kg}$ with a digital scale (model BF522W, Tanita Corporation, Tokyo, Japan), and waist and hip circumference to the closest $0.1 \mathrm{~cm}$ with a measuring tape (model 201, Seca). Two program staff collected and confirmed each measurement at each time point. An InBody 570 Multifrequency Bioelectrical Impedance Analyzer (Biospace, Inc, Seoul, Korea) was used to estimate skeletal muscle mass, body fat mass, and body fat percentage. InBody is comparable, 
$r=0.94(P<0.001)$ to dual-energy $\mathrm{x}$ ray absorptiometry to measure body composition. $^{18}$

Participants used a computer-assisted dietary recall method, the Automated Self-Administered 24hour dietary assessment tool (version 2018, National Cancer Institute, Bethesda, MD) to report dietary intake on 2 weekdays and 1 weekend day during each time point (T1, T2, and T3; a total of 9 recalls). ${ }^{19}$ These data were used to assess energy and macronutrient intake at each time point and were compared within-subject.

\section{Data Analysis}

The primary outcome measured in this study was the proportion of home-cooked meals consumed. The percentage of home-cooked meals consumed was calculated on the basis of the self-reported number of home-cooked meals divided by the self-reported total number of meals and for breakfast, lunch, or dinner. The secondary outcomes included cooking attitudes and cooking selfefficacy. Survey data for the cooking attitudes and cooking self-efficacy were coded and scored as described elsewhere (Michaud P, unpublished data "Development and Evaluation of Instruments to Measure the Effectiveness of a Culinary and Nutrition Education Program," Thesis, Clemson University, 2007). Dietary recalls were reviewed and cleaned per Automated Self-Administered 24-hour guidelines based on the 5th and 95th percentile of intakes for energy and specific nutrients. ${ }^{20}$ Two recalls were omitted on the basis of these guidelines. Because of the small sample size, this study did not meet the sample size guidelines for parametric tests. In addition, this study had a repeated measures design with the same individuals. Therefore, a Friedman's 2-way ANOVA test of differences by ranks was used as a nonparametric version of 1-way repeated measures ANOVA and reported as a chi-square value to test for statistical significance $(P \leq 0.05)$ among any of the 3-time points (T1, T2, and T3) (IBM SPSS Statistics for Mac, version 26, IBM Corp, Armonk, NY, 2019). If this test showed significance, a pairwise post hoc Dunn test was subsequently performed to determine if any 2 specific time points were significantly different at $P \leq$ 0.05 .

\section{RESULTS}

A total of 10 subjects (aged $46 \pm 11$ years) participated in and completed the study, with a majority being female (90\%). All were unmarried and had some college or technical school education.

Sixty percent of participants were White, not of Hispanic origin, 30\% were Asian or Pacific Islander, and 10\% were Hispanic/Latino. The majority were employed full-time (90\%), had a mean BMI of $31.7 \pm 9.4 \mathrm{~kg} / \mathrm{m}^{2}$, and self-reported being overweight by at least 5-10 pounds (90\%). Additional anthropometric and mean dietary intake data throughout the study period are reported in the Table. To determine whether AQMP affected the proportion of consumption of homecooked meals, the percent consumption of home-cooked meals was calculated in total, and for breakfast, lunch, or dinner, and then assessed by nonparametric ANOVA. Percent consumption of total home-cooked meals among the 3 time points differed $\left(\chi^{2}[2]=7.29, P=0.03\right)$, with an increase from T1 $(54 \pm 29 \%)$ to T2 (89 $\pm 8 \%)(P=0.03)$. Differences in percent consumption of home-cooked dinners were also seen among the 3-time points $\left(\chi^{2}[2]=7.80, P=0.02\right)$, with an increase in percent consumption of home-cooked dinners between $\mathrm{T} 1$ and T2 $(P=0.04)$ as shown in the Table.

Advance quantity meal preparation frequency $\left(\chi^{2}[2]=5.87, P=0.05\right)$, familiarity $\left(\chi^{2}[2]=12.19, \quad P=0.002\right)$, and confidence $\left(\chi^{2}[2]=10.83, \quad P=\right.$ $0.004)$ changed in response to the AQMP program. Specifically, AQMP frequency increased from $3.3 \pm 4.9$ sessions in the past 30 days at $\mathrm{T} 1$ to $7.1 \pm 6.0$ sessions in the past 30 days at $\mathrm{T} 2$, then decreased back to $5.4 \pm$ 5.9 sessions in the past 30 days at T3 $(P=0.05)$. Moreover, there were increases from T1 to T3 in both familiarity $(P=0.01)$ and confidence $(P=0.02)$ reported by the participants when using AQMP techniques. In addition, the program led to differences among the 3 time points for overall cooking attitudes $\left(\chi^{2}[2]=8.67, \quad P=0.03\right)$ and overall cooking self-efficacy $\left(\chi^{2}[2]=\right.$ $12.13, P=0.002$ ) (Table). Overall cooking attitude scores increased from $\mathrm{T} 1$ $(77.6 \pm 10.2)$ to $\mathrm{T} 3(85.3 \pm 12.6)$ $(P=0.01)$ and overall cooking self-efficacy scores increased from T1 (28 \pm $3.6)$ to $\mathrm{T} 2(31.8 \pm 3.7)(P=0.008)$.

\section{DISCUSSION}

This pilot study evaluated the effects of the group-based AQMP program on home-cooked meal consumption, cooking attitudes, and cooking selfefficacy. The results confirmed the hypothesis that a group-based AQMP strategy shows potential to increase home-cooked meal consumption and improve cooking attitudes, skills, and self-efficacy. Increases were seen in home-cooked meal consumption for total meals and dinners from preprogram to postprogram. Cooking attitudes and self-efficacy also increased postprogram. To the authors' knowledge, this is the first study to evaluate a program focused primarily on batch prep cooking. A quasi-experimental, longitudinal evaluation of a general cooking skills program found similar results with an increase in cooking confidence and a decrease in takeaway/fast food purchases preprogram and post a 10-week program. ${ }^{8,13}$ Home-cooked breakfast consumption increased, although not significantly, despite the AQMP program not providing breakfast for the participants. This finding may be attributed to increased motivation to eat more home-cooked meals as a by-product of the AQMP program, as observed in other group-based cooking studies. $^{8,10,13}$ It is also possible that the participants consumed their prepared AQMP meals for breakfast rather than for lunch or dinner.

When designing group-
based nutrition
programming, consider
including advanced
quantity meal preparation
to improve cooking
behaviors.

The greatest changes in cooking attitudes were related to the effort and energy required to cook. Participants 
Table. Home-Cooked Meal Consumption Rates, Cooking Attitudes and Self-Efficacy, Anthropometrics, and Energy and Macronutrient Intake in Healthy Adults Enrolled in a 6-Week Group AQMP Program $(n=10)$

\begin{tabular}{|c|c|c|c|c|c|c|c|}
\hline \multirow[b]{2}{*}{ Variable } & \multicolumn{2}{|c|}{ Preprogram (T1) } & \multicolumn{2}{|c|}{ Postprogram (T2) } & \multicolumn{2}{|c|}{3 Months Postprogram (T3) } & \multirow{2}{*}{$\frac{\chi^{2}(2)}{P \text { value }^{a}}$} \\
\hline & Mean & SD & Mean & SD & Mean & SD & \\
\hline \multicolumn{8}{|l|}{$\begin{array}{l}\text { Home-cooked meal consumption } \\
\text { proportion (\%) }\end{array}$} \\
\hline Breakfast & 70 & 36 & 76 & 43 & 87 & 31 & 0.09 \\
\hline Lunch & 42 & 35 & 92 & 10 & 69 & 32 & 0.052 \\
\hline Dinner & $52^{*}$ & 29 & $86^{*}$ & 14 & 70 & 30 & 0.02 \\
\hline Total meals & $54^{*}$ & 29 & $89^{*}$ & 8 & 76 & 29 & 0.03 \\
\hline \multicolumn{8}{|l|}{ Cooking behavior } \\
\hline Cooking attitudes score ${ }^{b}$ & $77.6^{\star}$ & 10.2 & 76.2 & 19.8 & $85.3^{*}$ & 12.6 & 0.01 \\
\hline Cooking self-efficacy score ${ }^{c}$ & $28.0^{\star}$ & 3.6 & $31.8^{*}$ & 3.7 & 31.3 & 4.2 & 0.002 \\
\hline \multicolumn{8}{|l|}{ Anthropometrics } \\
\hline Weight (kg) & $85.1^{*}$ & 27.8 & 83.6 & 27.4 & $83.3^{\star}$ & 27.4 & 0.03 \\
\hline Waist-to-hip ratio & 0.89 & 0.07 & 0.85 & 0.07 & 0.86 & 0.08 & 0.04 \\
\hline Skeletal muscle mass (kg) & 29.6 & 5.3 & 29.8 & 5.4 & 29.3 & 5.4 & 0.41 \\
\hline Body fat mass (kg) & $32.0^{*, \star \star}$ & 21.6 & $30.3^{*}$ & 21.4 & $28.6^{\star \star}$ & 22.4 & 0.01 \\
\hline Body fat (\%) & 34.8 & 11.0 & 33.6 & 11.9 & 33.9 & 12.0 & 0.08 \\
\hline Body mass index $\left(\mathrm{kg} / \mathrm{m}^{2}\right)$ & $31.7^{\star}$ & 9.4 & $31.1^{*}$ & 9.3 & 31.0 & 9.4 & 0.03 \\
\hline \multicolumn{8}{|l|}{ Energy and macronutrient intake } \\
\hline Energy intake (kcal) & $1,646.7$ & 626.7 & $1,574.0$ & 366.6 & $1,708.2$ & 655.2 & 0.72 \\
\hline $\begin{array}{l}\text { Estimated energy requirement } \\
(\% \text { intake) }\end{array}$ & 66.9 & 35.0 & 73.2 & 23.9 & 77.8 & 28.0 & 0.67 \\
\hline Protein intake (g) & 82.6 & 17.8 & 106.6 & 28.7 & 98.5 & 39.5 & 0.12 \\
\hline Fat intake (g) & 73.0 & 27.0 & 62.3 & 25.8 & 66.6 & 30.7 & 0.37 \\
\hline Carbohydrate intake (g) & 163.1 & 98.8 & 147.6 & 42.7 & 159.1 & 77.1 & 0.72 \\
\hline
\end{tabular}

AQMP indicates advance quantity meal preparation.

${ }^{\mathrm{a}} \mathrm{A}$ nonparametric Friedman test of differences on the basis of ranks was performed and reported as a chi-square value because of the small sample size and to account for repeated measures. A pairwise post hoc Dunn test was performed when the Friedman test was statistically significant at $P \leq 0.05$ to determine whether there were differences between time points; ${ }^{\mathrm{b}}$ Cooking Attitude scores range from 20 (negative) to 100 (positive); ${ }^{\circ}$ Cooking Self-Efficacy scores range from 7 (low) to 35 (high). Note: Groups with common superscript asterisks are significantly different on the basis of the pairwise post hoc Dunn test at $P \leq 0.05$.

in this study spent $4 \mathrm{~h} / \mathrm{wk}$ on AQMP, whereas Americans involved in meal preparation report spending an average of $7 \mathrm{~h} / \mathrm{wk}$ on meal preparation and clean-up. ${ }^{20}$ This result indicates that AQMP may help overcome the lack of time as a barrier to preparing homecooked meals.

Sustained changes in cooking behaviors are of interest. The overall attitudes of participants toward cooking increased, as well as familiarity, confidence, and use of AQMP 3 months after program completion. These findings are similar to other studies that examined cooking attitudes, reporting a more positive attitude toward cooking after completing a nutrition and cooking program. ${ }^{8,13,21}$ A 10-week community cooking skills program reported sustained attitudes and knowledge around cooking from baseline to 6 months postprogram. ${ }^{13}$ In addition,
2 studies that used the same cooking behavior assessment measure as this study, the Cooking With a Chef tool, reported significant increases in cooking self-efficacy, ${ }^{10,21}$ and 1 pilot study reported positive shifts in cooking attitudes from precourse to postcourse. ${ }^{21}$ Self-efficacy of the participants in the present study increased, suggesting a gain in cooking skill confidence during the course of the program.

\section{Developing cooking skills that include bulk meal prep may be an effective strategy to overcome barriers to home-cooked meal consumption.}

Nutrition education programs that incorporate cooking instruction have improved cooking behaviors and attitudes in lower-income populations. $^{22}$ Given the potential for meal prepping to reduce cooking costs, further research is warranted to determine the efficacy of AQMP programming focusing on low-cost recipe ingredients and minimal equipment. Recipes used in this AQMP program included steak, shrimp, and chicken breast as protein sources. Focusing on less expensive protein sources could lower food costs to target lower-income populations in future research. The AQMP program rented commercial kitchen space to accommodate 12 individuals. This additional cost may be minimized in facilities with established teaching kitchens.

Some limitations of this study included not having a control group and self-selection, thus not allowing 
for causal inferences. Participants were active members at a fitness center who were able to spend 4 hours and $\$ 100 /$ wk to participate in a cooking-related study. Although not measured, the motivation to change behaviors related to health and their socioeconomic status was higher than the general population. The survey, as a whole, was not validated beyond face validity. Energy needs were not considered when portioning meals, exemplary menus for diet quality were not used, and ad libitum food and beverage intake was allowed. The program facilitator procured all food and supplies, and therefore, participants did not have to practice food resource management skills such as meal planning, making lists, and grocery shopping. These steps could be a deterrent to AQMP at home. However, the 3 months postprogram results represented participants planning and acquiring food and supplies themselves. Finally, there was no power analysis and the small sample size of this study may have limited statistical power to detect sustained effects of AQMP on home-cooked meal consumption and cooking behaviors.

\section{IMPLICATIONS FOR RESEARCH AND PRACTICE}

To the authors' knowledge, this was the first study to examine the effects of AQMP on healthy adults. The results suggest the potential of AQMP as a strategy to increase the frequency of consumption of homecooked meals and increase positive cooking attitudes and cooking selfefficacy. With proper controls and a larger sample size, future research could confirm and build evidence for the efficacy of nutrition interventions that include AQMP as a strategy to overcome barriers to cooking and eating away from home.

\section{ACKNOWLEDGMENTS}

Partial financial support for the work reported was from a San José State University Circle of Friends grant to S.M. The authors acknowledge the technical support of Hsin Yi Teng in program facilitation and data collection. The source of all data presented in this manuscript was from the master's thesis of S.M.

\section{REFERENCES}

1. Expert Panel Members, Jensen MD, Ryan DH, et al. Executive summary: guidelines (2013) for the management of overweight and obesity in adults. Obesity. 2014;22:S5-S39.

2. Hales CM, Carroll MD, Fryar CD, Ogden CL. Prevalence of obesity among adults and youth: United States, 2015 -2016. NCHS Data Brief No. 288. US Department of Health and Human Services; 2017. https://www.cdc.gov/nchs/ data/databriefs/db288.pdf. Accessed October 6, 2020.

3. Saksena MJ, Okrent AM, Anekwe TD, et al. America's eating habits: food away from home. Economic Information Bulletin No. 196. https://www.ers.usda. gov/publications/pub-details/?pubid=90227. Accessed October 6, 2020.

4. Levy J, Auld G. Cooking classes outperform cooking demonstrations for college sophomores. J Nutr Educ Behav. 2004;36:197-203.

5. Mills S, Brown H, Wrieden W, White M, Adams J. Frequency of eating home cooked meals and potential benefits for diet and health: cross-sectional analysis of a population-based cohort study. Int J Behav Nutr Phys Act. 2017;14:1-11.

6. Tiwari A, Aggarwal A, Tang W, Drewnowski A. Cooking at home: a strategy to comply with U.S. dietary guidelines at no extra cost. Am J Prev Med. 2017; 52:616-624.

7. Wolfson JA, Bleich SN. Is cooking at home associated with better diet quality or weight-loss intention? Public Health Nutr. 2015;18:1397-1406.

8. Herbert J, Flego A, Gibbs L, et al. Wider impacts of a 10-week community cooking skills program - Jamie's ministry of food, Australia. BMC Public Health. 2014;14:1161.

9. Jordan KC, Freeland-Graves JH, KloheLehman DM, et al. A nutrition and physical activity intervention promotes weight loss and enhances diet attitudes in low-income mothers of young children. Nutr Res. 2008;28:13-20.
10. Warmin A, Sharp J, Condrasky MD. Cooking with a chef: a culinary nutrition program for college aged students. Top Clin Nutr. 2012;27:164-173.

11. Keller HH, Gibbs A, Wong S, Vanderkooy PD, Hedley M. Men can cook! Development, implementation, and evaluation of a senior men's cooking group. J Nutr Elder. 2004;24: 71-87.

12. Rock CL, Flatt SW, Sherwood NE, Karanja N, Pakiz B, Thomson CA. Effect of a free prepared meal and incentivized weight loss program on weight loss and weight loss maintenance in obese and overweight women: a randomized controlled trial. JAMA. 2010;304:1803-1810.

13. Flego A, Herbert J, Waters E, et al. Jamie's ministry of food: quasi-experimental evaluation of immediate and sustained impacts of a cooking skills program in Australia. PLoS One. 2014;9:e114673.

14. Macdiarmid JI, Loe J, Kyle J, McNeill G. "It was an education in portion size." Experience of eating a healthy diet and barriers to long term dietary change. Appetite. 2013;71:411-419.

15. Pelletier JE, Laska MN. Balancing healthy meals and busy lives: associations between work, school, and family responsibilities and perceived time constraints among young adults. J Nutr Educ Behav. 2012;44:481-489.

16. US Department of Health and Human Services and US Department of Agriculture. 2015 - 2020 Dietary Guidelines for Americans. 8th ed. US Department of Health and Human Services and US Department of Agriculture; 2015. https://health.gov/our-work/foodnutrition/previous-dietary-guidelines/ 2015. Accessed January 13, 2021.

17. Condrasky MD, Williams JE, Catalano PM, Griffin SF. Development of psychosocial scales for evaluating the impact of a culinary nutrition education program on cooking and healthful eating. J Nutr Educ Behav. 2011;43:511-516.

18. Miller RM, Chambers TL, Burns SP, Godard MP. Validating InBody ${ }^{\circledR} 570$ multi-frequency bioelectrical impedance analyzer versus DXA for body fat percentage analysis. Med Sci Sports Exerc. 2016;19:71-78.

19. Kirkpatrick SI, Subar AF, Douglass D, et al. Performance of the automated self-administered 24-hour recall relative 
to a measure of true intakes and to an interviewer-administered 24-h recall. Am J Clin Nutr. 2014;100:233-240.

20. US Bureau of Labor Statistics. American time use survey summary. https:// www.bls.gov/news.release/atus.nr0. htm. Accessed October 19, 2020.
21. Vanderpool LE, Trilk JL, Griffin SF, Condrasky MD. Culinary medicine: an evaluation to assess the knowledge, attitudes, behaviors, and confidence of firstyear medical students in a culinary medicine teaching kitchen. Top Clin Nutr. 2020;35:351-360.
22. Pooler JA, Morgan RE, Wong K, Wilkin MK, Blitstein JL. Cooking matters for adults improves food resource management skills and selfconfidence among low-income participants. J Nutr Educ Behav. 2017;49: 545-553.e1.

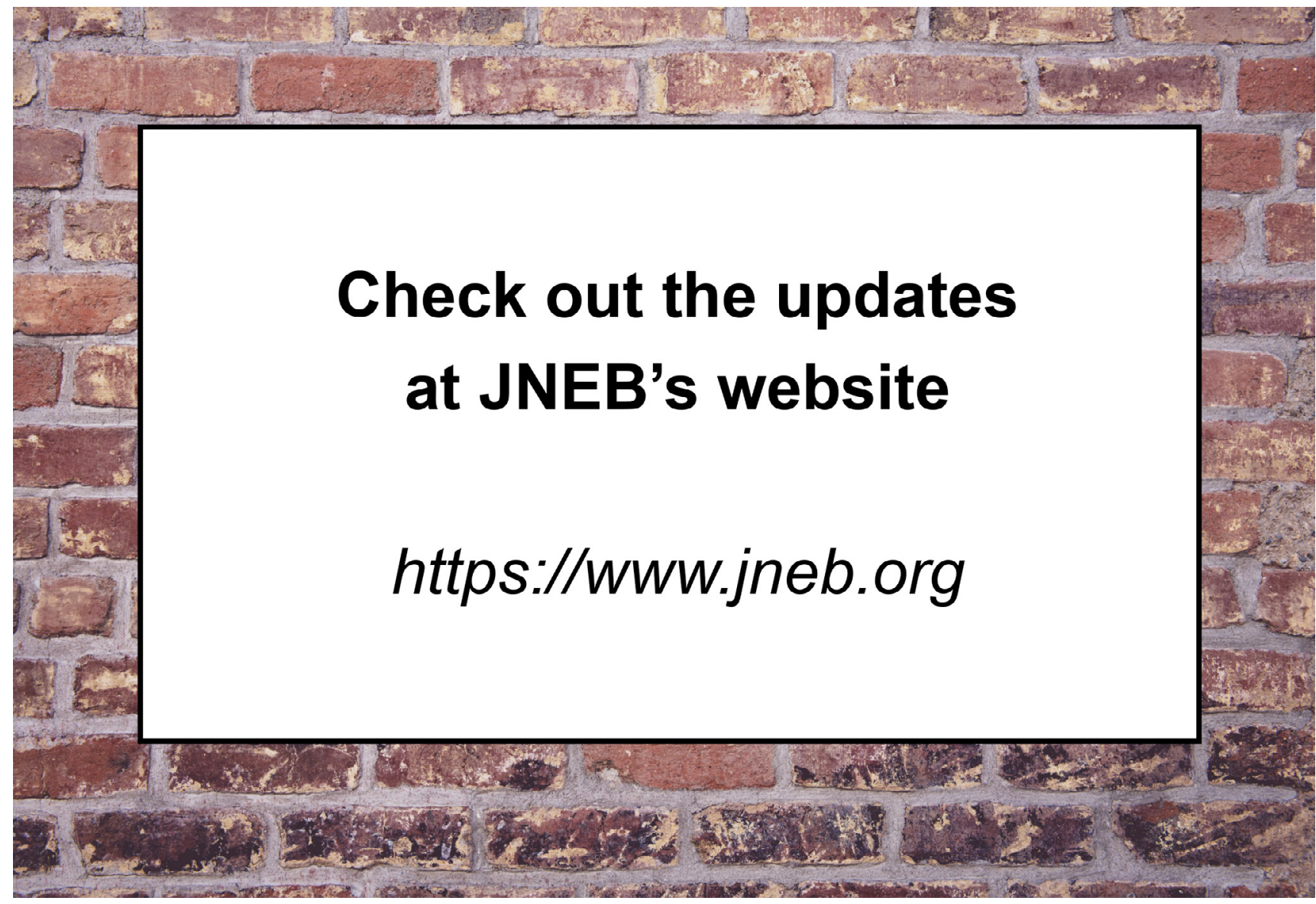

